\title{
Analisis Faktor Kesesuaian pada Teknologi SIMAK Dengan Tugas Dosen Menggunakan Model Task Technology Fit (Study Kasus: Universitas Tridinati Palembang)
}

\author{
A Bayu Rinaldo', Gusmelia Testiana², Rusmala Santi*3 \\ 1,2,3Program Studi Sistem Informasi, UIN Raden Fatah Palembang, Indonesia \\ Email: rinaldobayu123@gmail.com¹, gusmeliatestiana_uin@radenfatah.ac.id², \\ rusmalasanti_uin@radenfatah.ac.id ${ }^{3}$
}

\begin{abstract}
This study aims to determine the effect of the SIMAK task-technology fit factor on lecturers' assignments at Tridinati University, Palembang. This study used a sample of 124 respondents. The data collection method used questionnaires both offline and online. The data analysis technique used is PLS-SEM analysis. The results of this study indicate that the characteristics of task have an effect on task-technology fit, as evidenced by the t-statistic value which is greater than the t-table value of 13.622. In addition, the influence of the variable on the technology fit task model is $51.2 \%$, so based on this it can be concluded that SIMAK Online acceptance has been accepted by users.
\end{abstract}

Keywords: Task-Technology Fit, PLS-SEM, SIMAK

\section{PENDAHULUAN}

Kesesuaian tugas terhadap teknologi berhubungan dengan sejauh mana kemampuan individu menggunakan Teknologi Informasi untuk meningkatkan kinerja individu dalam menyelesaikan tugas. Universitas Tridinanti Palembang sebagai lembaga pendidikan tinggi telah menerapkan teknologi informasi sebagai sumber daya strategi yang penting salah satunya Sistem Informasi Akademik selanjutnya disebut SIMAK sudah digunakan semenjak tahun 2015 pada seluruh fakultas yang ada di Universitas(fakultas ekonomi, fakultas Teknik, fakultas pertanian, fakultas keguruan dan ilmu Pendidikan, dan pasca sarjana) bertujuan untuk meningkatkan kinerja organisasi. Pada hak akses dosen, SIMAK memiliki banyak fitur yang dapat mendukung dan mempermudah 
Vol. 1, No. 1, January 2020 e-ISSN: 2775-2496

https://journal-computing.org/index.php/journal-cisa/index

kegiatan dosen seperti menginputkan nilai mahasiswa, menginputkan RPS, menyetujui KRS mahasiswa. Fitur - fitur yang telah disediakan SIMAK tersebut dapat mempengaruhi kinerja dosen dalam melaksanakan tugas-tugas akademiknya.

Kinerja dosen merupakan faktor penting dalam pelaksanaan belajar mengajar di perguruan tinggi. Karena terdapat hubungan yang erat antara kinerja perseorangan dengan kinerja perusahaan/organisasi. Apabila kinerja dosen semakin baik, maka kinerja dari perguruan tinggi juga akan semakin baik. SIMAK dapat dikatakan sesuai akan tugas-tugas dosen, jika SIMAK dapat digunakan untuk meningkatkan kinerja dosen dalam menyelesaikan tugasnya, salah satu cara untuk mengetahui sejauh mana sebuah SIMAK dapat membantu dosen meyelesaikan tugasnya yang akan berdampak pada kinerjanya dengan melakukan analisis.

Dengan analisis pemecahan masalah dapat dilakukan karena menganalisis berarti menguraikan bagian-bagian komponen dengan mempelajari seberapa baik bagian-bagian komponen tersebut dapat bekerja atau berinteraksi untuk mencapai tujuan. Melakukan analisis memerlukan metode ataupun model sebagai pedoman dan acuan. model penelitian yang digunakan yaitu model Kesesuaian teknologi terhadap tugas (Task Technology Fit). Di dalam model Task Technology Fit ini sendiri terdiri dari 5 elemen, yaitu Task Characteristic (karakteristik tugas), Technology Characteristic (karakteristik teknologi), TaskTechnology Fit (kesesuaian tugas-teknologi), Utilization (pemanfaatan), dan Performance Impact (dampak kinerja). Namun pada penelitian ini tidak membahas pengaruh Technology Characteristic (karakteristik teknologi) terhadap Task-Technology Fit (kesesuaian tugas-teknologi) karena tempat penelitian yaitu Universitas Tridinanti Palembang sudah mempunyai teknologi pendukung yang tersedia dan memenuhi standar minimal teknologi yang harus dimiliki oleh sebuah universitas dimana jika memenuhi standar tersebut maka secara tidak langsung teknologi yang digunakan sudah sesuai dengan kebutuhan untuk menjalakan SIMAK. Selain itu penelitian ini juga tidak membahas pengaruh Utilization (pemanfaatan) terhadap Performance Impact (dampak kinerja) karena penggunaan SIMAK yang sudah berjalan lama di Universitas Tridinanti Palembang yang secara tidak langsung menunjukan bahwa SIMAK mempunyai dampak kinerja yang sudah jelas bagi Universitas Tridinanti Palembang. 
Vol. 1, No. 1, January 2020 e-ISSN: 2775-2496

https://journal-computing.org/index.php/journal-cisa/index

Berdasarkan uraian diatas, maka akan dilakukan penelitian tentang kesesuaian teknologi terhadap tugas dosen di Universitas Tridinanty Palembang menggunakan model Task Technology Fit yang dikembangkan Goodhue dan Thomson 1995.

\section{METODOLOGI PENELITIAN}

Metode dalam penelitian ini menggunakan pendekatan kuantitatif karena data penelitian berupa angka-angka dan di analisis menggunakan statistic(Sugiyono 2016). Penelitian ini dilakukan dengan menyebarkan kuesioner. Peryataan didapatkan dari variabel berdasarkan studi literatur, responden penelitian ini adalah dosen tetap maupun dosen luar biasa pada Universitas Tridinati Palembang. Penelitian ini menggunakan Teknik analisis data PLS-SEM dengan mengadopsi model Task Technology Fit(Goodhue, D.L, dan Thompson 1995).

\subsection{Model Task Technology Fit}

Model penelitian kesesuaian teknologi terhadap tugas (Task-Technology Fit) adalah kesesuaian antara fungsi dari teknologi dan kebutuhan tugas pengguna, di mana teknologi yang ada dimanfaatkan untuk mendukung tugas-tugas pengguna sehari-hari. Inti dari model ini adalah bahwa teknologi informasi memiliki dampak positif pada kinerja individu, teknologi harus dimanfaatkan, dan teknologi harus sesuai terhadap tugas pengguna(Widagdo and Cahyadi 2019). Model Task Technology Fit dapat dilihat pada gambar 1.

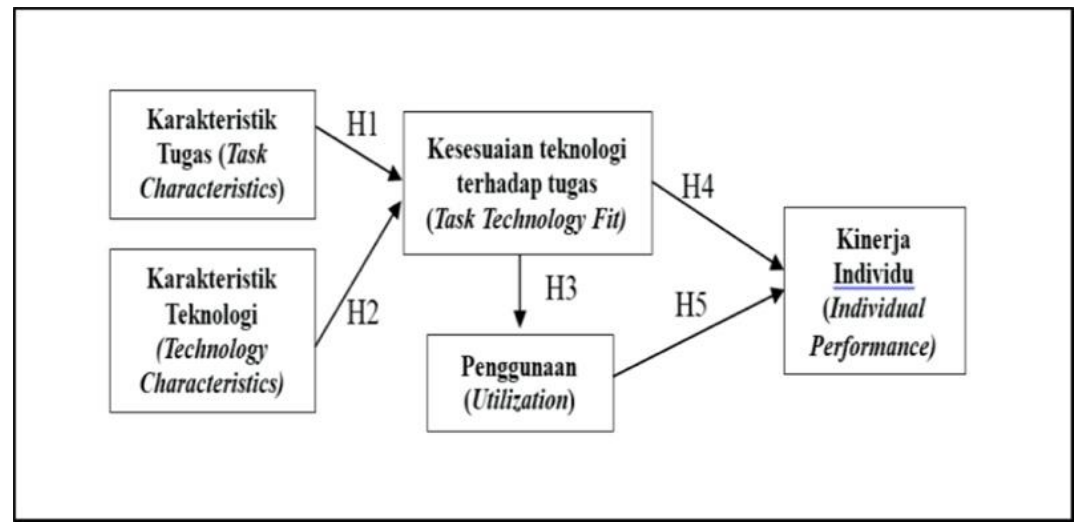

Gambar 1. Model Task Technology Fit

(Goodhue \& Thompso, 1995 dalam putut pamilih,2018) 


\subsection{Partial Least Square - Structural Equation Model (PLS - SEM)}

Menurut (Ghozali 2016), PLS merupakan pendekatan alternatif yang bergeser dari pendekatan SEM berbasis covariance menjadi berbasis varian. SEM yang berbasis kovarian umumnya menguji kausalitas atau teori sedangkan PLS lebih bersifat predictive model. Namun ada perbedaan antara SEM berbasis covariance based dengan component based PLS adalah dalam penggunaan model persamaan struktural untuk menguji teori atau pengembangan teori yang bertujuan prediksi.

\subsection{Populasi dan Sampel}

Populasi dari penelitian ini adalah semua dosen pengguna akhir dari SIMAK di Universitas Tridinati Palembang yang terdiri dari 179 dosen tetap dan dosen luar biasa.

Peneliti menggunakan rumus slovin sedangkan untuk taraf signifikasi (d) didasarkan atas pertimbangan peneliti artinya boleh dipilih apakah 0,01 $(1 \%)$ atau $0,05(5 \%)$ atau $0.1(10 \%)$ (Riadi 2016). Jadi dalam penelitian ini digunakan taraf siginifikasi sebesar 5\% dari total populasi sebanyak 179 maka didapatkan jumlah sampel sebanyak 124 sampel. Berikut penghitungannya menggunakan rumus Slovin, Diketahui:

$$
\begin{aligned}
& \mathrm{n}=\frac{\mathrm{N}}{1+\left(\mathrm{N} \mathrm{x} \mathrm{e}^{2}\right)} \\
& \mathrm{N}=179 \\
& \mathrm{e}=5 \%(0,05) \\
& \mathrm{n}=\frac{\mathrm{N}}{\mathrm{N}(\mathrm{E})^{2}+1}=\frac{179}{179(0,05)^{2}+1}=\frac{179}{1,4475}=123,662=124 \text { Sampel }
\end{aligned}
$$

Teknik pengambilan sampel yang digunakan adalah probability sampling dengan jenis proportion adestratified random sampling. Alasan teknik ini digunakan adalah karena dapat memperkecil error, meningkatkan peluang setiap strata yang terwakili dalam sampel, selain itu juga agar mendapatkan ketepatan yang lebih tinggi, karena stratifikasi akan menghasilkan akurasi yang baik dalam melakukan penilaian terhadap populasi. Berikut dijelaskan penghitungannya: 
Vol. 1, No. 1, January 2020 e-ISSN: 2775-2496

https://journal-computing.org/index.php/journal-cisa/index

$\begin{array}{ll}\text { Dosen tetap } & =\frac{\text { Jumlah Populasi Dosen Tetap }}{\text { Total Seluruhnya }} \times \\ \text { Jumlah Sampel } & =\frac{130}{179} \times 124=90,05=90 \text { Sampel } \\ \text { Dosen luar biasa } & =\frac{\text { Jumlah Populasi Dosen Luar biasa }}{\text { Total Seluruhnya }} \times \\ \text { Jumlah Sampel } & =\frac{49}{179} \times 124=33,94=34 \text { Sampel }\end{array}$

\subsection{Kerangka Konseptual dan Hipotesis Penelitian}

\subsubsection{Kerangka Konseptual}

Teori utama yang digunakan pada penelitian ini menggunakan teori Task- Technology Fit yang dikemukakan oleh Goodhue and Thompson (1995). Penelitian ini menjelaskan tentang pengaruh langsung Task Characteristic terhadap Task-Technology Fit dan pengaruh tidak langsung Task Characteristic terhadap Utilization dan Performance. Dalam penelitian ini tidak membahas hubungan Technology Characteristic terhadap Task-Technology Fit serta tak membahas hubungan Utilization terhadap Performance terhadap. Kerangka konseptual dapat dilihat pada gambar 2.

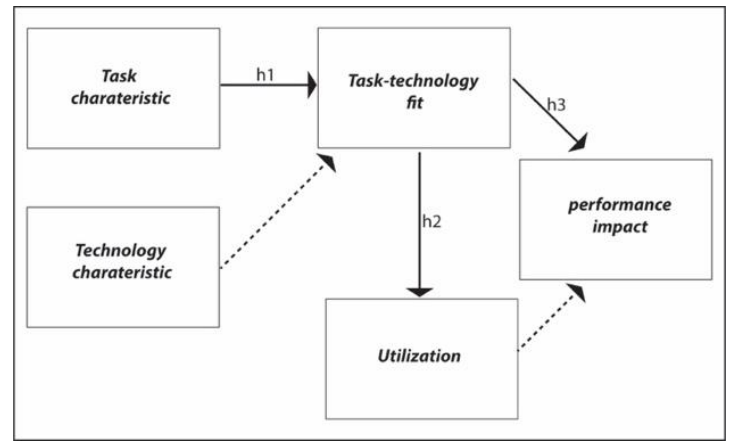

Gambar 2. Kerangka Konseptual

\subsubsection{Hipotesis Penelitian}

Berdasarkan rumusan masalah, teori-teori pendukung dan kerangka konseptual yang dipaparkan, maka hipotesis yang diajukan dapat dilihat pada Gambar 3. 
Vol. 1, No. 1, January 2020 e-ISSN: 2775-2496

https://journal-computing.org/index.php/journal-cisa/index

\begin{tabular}{|l|l|l|}
\hline No & \multicolumn{2}{|c|}{ Hipotesis penelitian } \\
\hline 1. & $\mathrm{H}_{0}$ & $\begin{array}{l}\text { Task Characteristic tidak berpengaruh } \\
\text { langsung terhadap task technology fit }\end{array}$ \\
\cline { 2 - 4 } & $\mathrm{H}_{\mathrm{a}}$ & $\begin{array}{l}\text { Task Characteristic berpengaruh langsung } \\
\text { terhadap task technology fit }\end{array}$ \\
\hline 2. & $\mathrm{H}_{0}$ & $\begin{array}{l}\text { Task technology fit tidak berpengaruh } \\
\text { langsung terhadap utiliztion }\end{array}$ \\
\cline { 2 - 4 } & $\mathrm{H}_{\mathrm{a}}$ & $\begin{array}{l}\text { Task technology fit berpengaruh langsung } \\
\text { terhadap utiliztion }\end{array}$ \\
\hline 3. & $\mathrm{H}_{0}$ & $\begin{array}{l}\text { Task technology fit tidak berpengaruh } \\
\text { langsung terhadap performance impact }\end{array}$ \\
\cline { 2 - 4 } & $\mathrm{H}_{\mathrm{a}}$ & $\begin{array}{l}\text { Task technology fit berpengaruh langsung } \\
\text { terhadap performance impact }\end{array}$ \\
\hline
\end{tabular}

Gambar 3. Hipotesis Penelitian

Hasil pengambilan keputusan hipotesis terkait dengan keputusan tentang penerimaan dan penolakan hipotesis yang didasarkan dari perbandingan nilai hitung uji yang digunakan dengan standar tabel (sesuai dengan uji yang digunakan) atau dapat dilakukan dengan membandingkan taraf signifikansi yang diinginkan berdasarkan alpha $(\alpha)$ (Windarti 2015).

\subsection{Tahapan Penelitian}

Tahapan Penelitian menggambarkan proses penelitian yang akan ditempuh sekaligus menggambarkan penelitian secara keseluruhan. Tahapan penelitian dapat dilihat dalam Gambar 4.

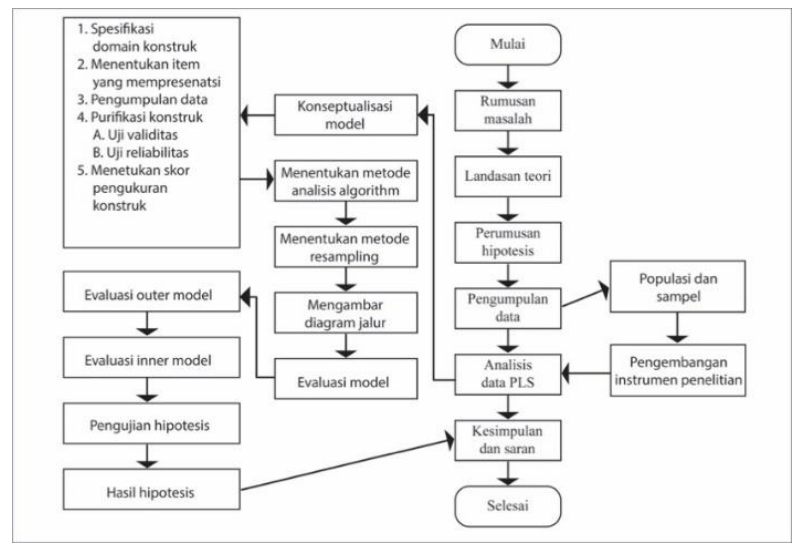

Gambar 4. Tahapan Penelitian

((berdasarkan Sugiyono,2015) 


\section{HASIL DAN PEMBAHASAN}

\subsection{Deskripsi Responden}

\section{1) Responden Berdasarkan Jenis Kelamin}

\section{RESPONDEN BERDASARKAN JENIS KELAMIN}

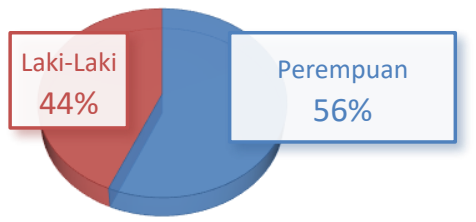

Gambar 5 Diagram Pie Berdasarkan Jenis Kelamin (Sumber: Hasil Pengolahan Data)

Berdasarkan Gambar 5, bahwa 56\% responden perempuan, 44\% responden laki-laki. Dapat disimpulkan bahwa pengguna sistem informasi akademik didominasi oleh jenis kelamin perempuan sebanyak 70 orang atau $56 \%$ dari jumlah keseluruhan.

\section{2) Responden Berdasarkan Usia}

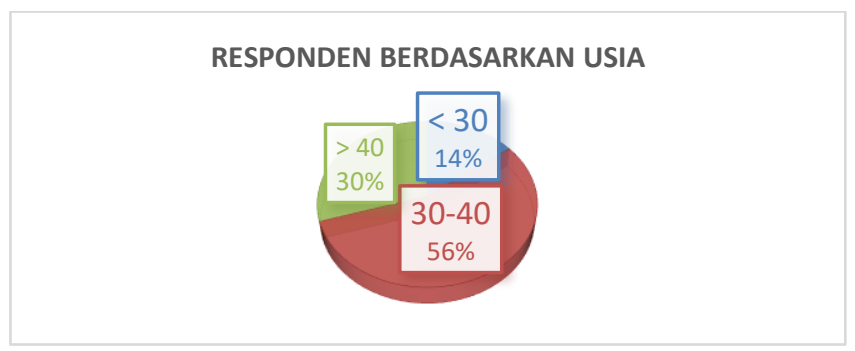

Gambar 6 Diagram Pie Berdasarkan Usia

(Sumber: Hasil Pengolahan Data)

Berdasarkan Gambar 6, bahwa 56\% responden berusia diantara 30-40 tahun, 30\% responden berusia diatas 40 tahun dan 14\% responde berusia dibawah 30 tahun. Dapat disimpulkan bahwa pengguna sistem informasi akademik didominasi oleh usia 30 sampai 40 tahun sebanyak 63 orang atau $56 \%$ dari jumlah keseluruhan. 
Vol. 1, No. 1, January 2020 e-ISSN: 2775-2496

https://journal-computing.org/index.php/journal-cisa/index

\section{3) Responden Berdasarkan Status Pekerjaan}

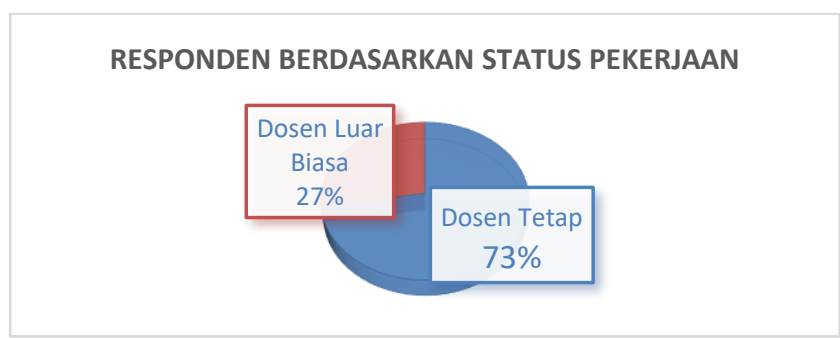

Gambar 7 Diagram Pie Status Pekerjaan

(Sumber: Hasil Pengolahan Data)

Berdasarkan Gambar 7, bahwa 73\% responden adalah dosen tetap, 27\% responden dosen luar biasa. Dapat disimpulkan bahwa pengguna sistem informasi akademik didominasi oleh dosen tetap sebanyak 90 orang atau $73 \%$ dari jumlah keseluruhan.

\section{4) Responden Berdasarkan Pendidikan}

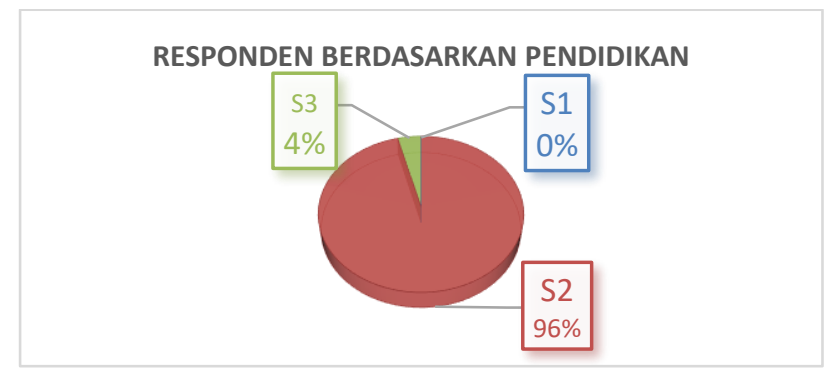

Gambar 8 Diagram Pie Pendidikan

(Sumber: Hasil Pengolahan Data)

Berdasarkan Gambar 8, bahwa 96\% responden adalah dosen yang berpendidikan S2, 4\% responden dosen bependidikan S3 dan tidak ada responden yang berpendidikan S1. Dapat disimpulkan bahwa pengguna sistem informasi akademik didominasi oleh dosen berpendidikan S2 sebanyak 119 orang atau $96 \%$ dari jumlah keseluruhan.

\subsection{Evaluasi Outer Model}

Evaluasi outer model atau model pengukuran dilakukan untuk mengukur validitas dan reliabilitas model. Outer model dengan indikator refleksif 
Vol. 1, No. 1, January 2020 e-ISSN: 2775-2496

https://journal-computing.org/index.php/journal-cisa/index

dievaluasi dengan melihat nilai convergent validity, discriminant validity, dan composite reliability.

\section{1) Uji Validitas}

Uji validitas dapat dinilai dengan melihat nilai convergent validity dan discriminant validity. convergent validity dapat nilai dengan melihat nilai AVE(Average Variance Extacted) setiap konstruk harus lebih besar dari 0.5 maka rata-rata konstuk dapat menjelakan lebih dari $50 \%$ varian setiap indicator.

Tabel 1 Output Nilai AVE

\begin{tabular}{lcc}
\hline \multicolumn{1}{c}{ Nama Variabel } & AVE & Akar AVE \\
\hline Task Characteristic (X1) & 0.628 & 0.792 \\
Technology Characteristic (X2) & 0.767 & 0.876 \\
Task-Technology Fit (Y1) & 0.512 & 0.716 \\
Utilization (Y2) & 0.740 & 0.860 \\
Performance Impact (Y3) & 0.800 & 0.894 \\
\hline
\end{tabular}

(Sumber: Hasil Pengolahan Data)

Berdasarkan Tabel 1, dapatkan dikatakan semua konstruk dalam model convergent validity karena semua nilai AVE lebih besar dari 0.5. sedangkan untuk menilai discriminant validity jika akar AVE untuk setiap konstruk lebih tinggi daripada nilai latent variable correlation.

Tabel 2 Output Output Latent Variable Correlation

\begin{tabular}{cccccc}
\hline & X1 & X2 & Y1 & Y2 & Y3 \\
\hline Task Characteristic (X1) & 1.000 & 0.375 & 0.711 & -0.227 & -0.212 \\
Technology Characteristic (X2) & 0.375 & 1.000 & 0.339 & -0.040 & -0.166 \\
Task-Technology Fit (Y1) & 0.711 & 0.339 & 1.000 & -0.034 & -0.095 \\
Utilization (Y2) & -0.227 & -0.040 & -0.034 & 1.000 & 0.712 \\
Performance Impact (Y3) & -0.212 & -0.166 & -0.095 & 0.712 & 1.000 \\
\hline
\end{tabular}

(Sumber: Hasil Pengolahan Data) 
Vol. 1, No. 1, January 2020 e-ISSN: 2775-2496

https://journal-computing.org/index.php/journal-cisa/index

Berdasarkan perbandingan dari kedua tabel diatas, dapat dilihat bahwa akar AVE setiap konstruk lebih tinggi dibandingkan dengan nilai korelasi setiap konstruk terhadap konstruk lainnya. Jadi dapat disimpulkan bahwa semua konstruk dalam model yang diestimasi memenuhi kriteria discriminant validity.

\section{2) Uji Reliabilitas}

Uji reliabilitas konstruk dapat nilai dengan composite reliability lebih besar 0,70 .

Tabel 3 Output Composite Reliability

\begin{tabular}{lc}
\hline & $\begin{array}{c}\text { Composite } \\
\text { Reliability }\end{array}$ \\
\hline Task Characteristic (X1) & 0.770 \\
Technology Characteristic (X2) & 0.868 \\
Task-Technology Fit (Y1) & 0.947 \\
Utilization (Y2) & 0.850 \\
Performance Impact (Y3) & 0.889 \\
\hline
\end{tabular}

(Sumber: Hasil Pengolahan Data)

Berdasarkan tabel diatas, maka dapat disimpulkan bahwa masing-masing konstruk bernilai diatas 0,70 yang artinya semua konstruk memiliki reliabilitas yang baik.

\subsection{Evaluasi Inner Model}

\section{1) Menggambarkan Diagram Jalur}

Pada penelitian ini metode analisis algorithm yang digunakan peneliti adalah PLS Algorithm pada smartPLS 3.0 dengan skema algorithm path yang disarankan oleh Wold. 
Vol. 1, No. 1, January 2020 e-ISSN: 2775-2496

https://journal-computing.org/index.php/journal-cisa/index

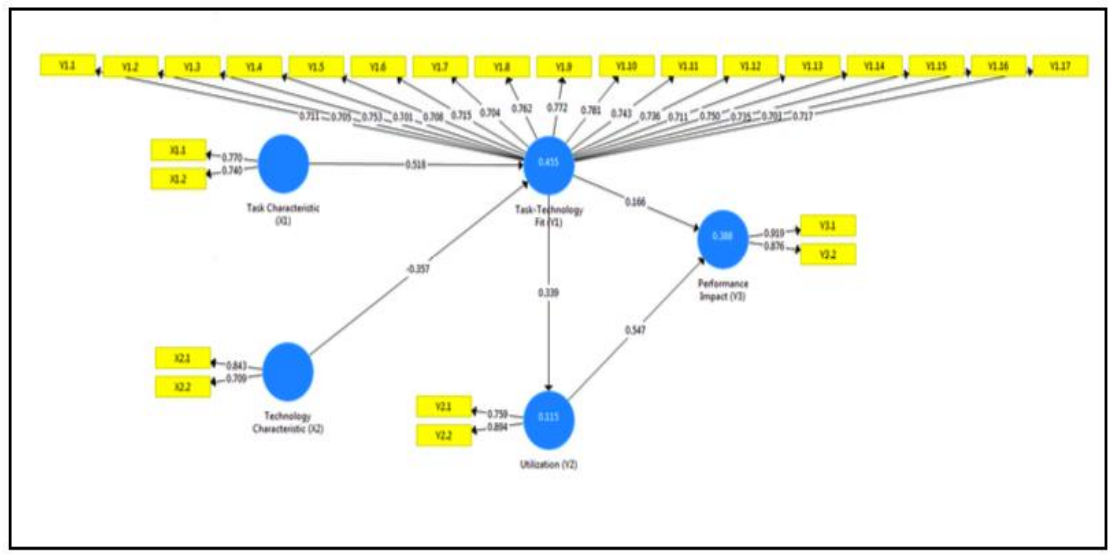

Gambar 9 Model Eksekusi

Berdasarkan gambar 9 bahwa semua indikator dinyatakan valid.

\section{2) R-Square}

Penggujian R-Square dapat dilakukan dengan melihat nilai R-Squares pada variabel endogen (terikat). Perubahan nilai R-square dapat digunakan untuk menjelaskan pengaruh variabel eksogen terhadap variabel endogen apakah mempunyai pengaruh yang sebenarnya. Rsquare $(R 2)>0,67$ menunjukan bahwa model "kuat", R-square $(R 2)>$ 0,33 dan $<0,67$ menunjukan bahwa model "moderat", dan R-square $(R 2)$ $<0,19$ menunjukan bahwa model "lemah".

Tabel 4 Output R Square( $\left.R^{2}\right)$

\begin{tabular}{lc} 
& R Square \\
\hline Task-Technology Fit (Y1) & 0.512 \\
Utilization (Y2) & 0.001 \\
Performance Impact (Y3) & 0.512 \\
\hline \multicolumn{2}{c}{ (Sumber: Hasil Pengolahan Data) }
\end{tabular}

Berdasarkan Tabel 4 bahwa dua variabel termasuk kategori "kuat" yaitu variabel Task-Technology Fit (Y1) dan Performance Impact (Y3) dan satu variabel termasuk kategori "lemah" yaitu variabel Utilization. 


\section{3) Q-Square}

Q-Square dapat diperoleh melalui perhitungan berikut:

$Q 2=1-[(1-R Y 1)(1-R Y 2)(1-R Y 3)]$

$Q 2=1-[(1-0,512)(1-0,001)(1-0,330)(1-0,512)$

$Q 2=[1-(0,488)(0,999)(0,488)]$

$Q 2=1-0,238$

$Q 2=0,76$ atau $\mathbf{7 6} \%$

Dari hasil perhitungan diperoleh nilai Q-Squares sebesar 0,72. Hal ini menunjukan bahwa model mempunyai predictive relevance.

\section{4) Signifikasi (Two Tailed)}

Tabel 5 Output Signifikansi Kroteria PLS - SEM

\begin{tabular}{llll}
\hline & $\begin{array}{l}\text { T Statistics } \\
(\mid \mathbf{0} / \text { STDEV } \mid)\end{array}$ & T-Value & Keterangan \\
\hline X1 -> Y1 & 13.622 & 1,96 & Ho ditolak \\
Y1 -> Y2 & 0.334 & 1,96 & Ho diterima \\
Y1 -> Y3 & 1.352 & 1,96 & Ho diterima \\
\hline
\end{tabular}

(Sumber: Hasil Pengolahan Data)

Berdasarkan Tabel 5 dapat diketahui terdapat 2 hipotesis yang diterima dan 1 hipotesis yang ditolak berdasarkan perbandingan nilai t-statistics dengan nilai t-value dimana jika nilai t-statistics $>t$-value maka hipotesis ditolak dan jika nilai t-statistics $<\mathrm{t}$-value maka hipotesis diterima.

\section{5) Goodness of Fit}

Goodness of Fit yang dapat dihitung dari nilai akar AVE dan dengan nilai R-Squares. Adapun perhitungan bisa dilihat sebagai berikut:

$$
\begin{aligned}
& G o F=\sqrt{\overline{A V E} \times \overline{\mathrm{R}^{2}}} \\
& G o F=\sqrt{0,689 \times 0,342} \\
& G o F=\sqrt{0,235} \\
& G o F=\mathbf{0}, 484
\end{aligned}
$$


Vol. 1, No. 1, January 2020 e-ISSN: 2775-2496

https://journal-computing.org/index.php/journal-cisa/index

Dari hasil uji GoF didapat hasil sebesar 0,484. Jadi, dapat disimpulkan bahwa model yang ada didalam penelitian ini large(besar) sehingga pengujian hipotesa dapat dilakukan.

\section{6) Pengujian Hipotesis}

Pengujian hipotesis antar konstruk endogen terhadap konstruk eksogen dan konstruk eksogen terhadap konstruk eksogen dilakukan dengan metode resampling bootstraping. Pengujian hipotesis dapat dilihat dari besarnya nilai T-statistik. Batas untuk menolak dan menerima hipotesis yang diajukan adalah 1,654 yang dilihat dari $t$ tabel dengan tingkat signifikan sebesar $5 \%$.

Tabel 6 Output Path Coefficient

\begin{tabular}{llcl}
\hline & $\begin{array}{l}\text { T Statistics } \\
(\mid \mathbf{0} / \text { STDEV } \mid)\end{array}$ & T-Value & Keterangan \\
\hline $\mathbf{X 1}$-> Y1 & 13.622 & 1,96 & Ho ditolak \\
$\mathbf{Y 1 ~}->$ Y2 & 0.334 & 1,96 & Ho diterima \\
$\mathbf{Y 1}$-> Y3 & 1.352 & 1,96 & Ho diterima \\
\hline \multicolumn{4}{l}{ (Sumber: Hasil Pengolahan Data) }
\end{tabular}

Berdasarkan Tabel 5 dapat diketahui terdapat 2 hipotesis yang diterima dan 1 hipotesis yang ditolak.

\subsection{Pembahasan}

\section{1) Pengaruh Task Charateristic (X1) Terhadap Task Technology Fit (Y1)}

Berdasarkan pengujian hipotesis yang telah dilakukan didapat bawah adanya pengaruh antara variabel X1 terhadap Y1 dengan nilai koefisien sebesar 0,680. Hal ini dibuktikan dari besarnya t-hitung $>\mathrm{t}$-tabel yaitu 13,622 > 1,654. Jadi, dapat disimpulkan bahwa Ho ditolak.

\section{2) Pengaruh Terhadap Task Technology Fit (Y1) Terhadap Utilization(Y2)}

Berdasarkan pengujian hipotesis yang telah dilakukan didapat bawah tidak terdapat pengaruh antara variabel Y1 terhadap Y2 dengan nilai koefisien sebesar $-0,034$. Hal ini dibuktikan dari kecilnya t-hitung $<\mathrm{t}$ tabelyaitu $0,034<1,654$. Jadi, dapat disimpulkan bahwa Ho diterima 
Vol. 1, No. 1, January 2020 e-ISSN: 2775-2496

https://journal-computing.org/index.php/journal-cisa/index

\section{3) Pengaruh Terhadap Task Technology Fit (Y1) Terhadap Perpormace Impact (Y2)}

Berdasarkan pengujian hipotesis yang telah dilakukan didapat bawah tidak terdapat pengaruh antara variabel Y1 terhadap Y3 dengan nilai koefisien sebesar -0,071. Hal ini dibuktikan dari kecilnya t-hitung $<\mathrm{t}$ tabel yaitu 1,352<1,654. Jadi, dapat disimpulkan bahwa Ho diterima.

\section{CONCLUSION}

Berdasarkan penelitian yang telah dilakukan dapat diambil simpulan yaitu:

1) Hasil pengolah data dengan menggunakan SmartPLS dan model Task Technology Fit menunjukkan bahwa SIMAK Online pada Universitas Tridinanty Palembang sudah diterima dengan besar nilai penerimaan yaitu sebesar $51,2 \%$.

2) Faktor-faktor yang berpengaruh dalam kesesuaian teknologi terhadap tugas dosen di Universitas Tridinanty Palembang yaitu, variabel Task Characteristic (X1) terhadap variabel Task Technology Fit (Y1) sebesar 13,622 dikarenakan nilai t-statistiknya yang lebih besar dari nilai t-tabelnya. Sedangkan untuk variabel yang tidak berpengaruh terhadap kesesuaian teknologi yaitu variabel Task Technology Fit (Y1) terhadap variabel Utilization (Y2) sebesar 0,334 dan variabel Task Technology Fit (Y1) terhadap variabel Performance Impacts (Y3) sebesar 1.352 karena nilai tstatistiknya yang lebih kecil dari nilai t-tabelnya. Untuk nilai pengaruh variabel yang paling tinggi dalam kesesuaian teknologi terhadap tugas dosen di Universitas Tridinanty Palembang adalah variabel Task Characteristic (X1) terhadap Task Technology Fit (Y1) sebesar 13,622 sedangkan untuk nilai pengaruh variabel yang paling rendah adalah variabel Task Technology Fit (Y1) terhadap Utilization (Y2) sebesar 0,334.

\section{DAFTAR PUSTAKA}

Ghozali, Imam. 2016. "Aplikasi Analisis Multivariate Dengan Program IBM SPSS 23." (Edisi 8). Semarang: Badan Penerbit Universitas Diponegoro.

Goodhue, D.L, dan Thompson, R. .. 1995. "Task-Technology Fit and Individual Performance." Pp. 213-36 in MIS Quarterly. Vol. 19.

Riadi, Edi. 2016. "Statistika Penelitian (Analisis Manual Dan IBM SPSS)." in Statistika Penelitian (Analisis Manual dan IBM SPSS). 
Vol. 1, No. 1, January 2020 e-ISSN: 2775-2496

https://journal-computing.org/index.php/journal-cisa/index

Sugiyono. 2016. Metode Penelitian Pendidikan (Pendekatan Kuantitatif, Kualitatif Dan R\&D). Bandung: Alfabeta.

Widagdo, Putu Pamilih. 2018. "Pengaruh Task Technology Fit Pada Generasi X (1965-1980) Dalam Menggunakan Teknologi Cloud Strorage. "Jurtis.vol1 ISSN 2579-8780

Widagdo, Putut Pamilih, and Dedy Cahyadi. 2019. "Kesesuaian Teknologi Cloud Storage Terhadap Tugas Pada Generasi Y (1981-2000) Yang Berdampak Terhadap Kinerja Individu." Informatika Mulawarman: Jurnal Ilmiah Ilmu Komputer 14(1):32. doi: 10.30872/jim.v14i1.1853.

Windarti, Windarti. 2015. "Pengaruh Karakteristik Pengelola Keuangan Sekolah Dan Transparansi Terhadap Efektivitas Pengelolaan Keuangan Pada Sma Dan Smk Negeri Di Kota Madiun." Assets: Jurnal Akuntansi Dan Pendidikan. doi: 10.25273/jap.v4i1.671. 